\title{
EOG - Based Computer Control System for People with Mobility Limitations
}

\author{
Cemil Keskinoğlu ${ }^{1 *}$, Ahmet Aydın² \\ 1* Çukurova University, Faculty of Engineering, Departmant of Biomedical Engineering, Adana, Turkey, (ORCID: 0000-0003-3161-3427), ckeskinoglu@cu.edu.tr \\ ${ }^{2}$ Çukurova University, Faculty of Engineering, Departmant of Biomedical Engineering, Adana, Turkey, (ORCID: 0000-0003-2390-7556), aaydin@ cu.edu.tr
}

(3rd International Congress on Human-Computer Interaction, Optimization and Robotic Applications June 11-13, 2021)

(DOI: $10.31590 /$ ejosat.948124)

ATIF/REFERENCE: Keskinoğlu, C. \& Aydın, A. (2021). EOG - Based Computer Control System for People with Mobility Limitations. European Journal of Science and Technology, (26), 256-261.

\begin{abstract}
Computer usage is an essential task that is required in almost every aspect of life today. As technology develops, this task becomes more and more necessary in the broader area. This task, which is quite simple for healthy people, has difficulties for people with muscular diseases or limited mobility. It is essential to use a computer not to have problems in their daily lives and adaptions. In this study, a computer control system was designed so that people with diseases such as ALS and paralysis can control computers easily. This system controls the mouse cursor according to the signal obtained by using the person's EOG signals. In this way, such people can control the computer without using their hands. In the study, the obtained EOG signals were amplified with an instrumentation amplifier and filtered digitally, thus it is ensured that the system can perform successfully. The designed system has great ease of use as it is a microcontroller-based and portable system and has a small size. In addition to the hardware, the embedded software necessary for the system's control has also been developed. With this designed system, people with limited mobility will easily use computers with only glasses in their daily lives.
\end{abstract}

Keywords: ALS, EOG, Human-computer interface, Microcontroller, Digital filtering.

\section{Hareket Kabiliyeti Sınırlı Kişiler için EOG Tabanlı Bilgisayar Kontrol Sistemi}

\section{$\ddot{O z}$}

Bilgisayar kullanımı günümüzde hayatın neredeyse her alanında gerekmekte olan temel bir iştir. Teknoloji geliştikçe bu iş daha da geniş bir alanda gerekli olmaktadır. Sağlıklı insanlar için oldukça basit olan bu iş kas hastalıklarına sahip veya hareket kabiliyeti sınırlı olan kişiler için zorluklara sahiptir. Bu tür kişilerin gündelik işlerinde sorun yaşamaması ve hayata adaptasyonları için bilgisayar kullanabilmeleri ise oldukça önemlidir. Yapılan çalışmada ALS, felç gibi hastalıklara sahip kişilerin kolay şekilde bilgisayar kullanabilmeleri için, bir bilgisayar kontrol sistemi tasarlanmıştır. Bu sistem kişinin EOG işaretlerini kullanarak bilgisayar faresinin kontrolünü sağlamaktadır. Bu sayede böyle kişiler ellerini kullanmadan bilgisayarı kontrol edebilmektedir. Çalışmada elde edilen EOG sinyalleri bir enstrumantasyon yükselteci ile yükseltilmiş ve dijital olarak filtrelenerek bu sayede sistemin başarılı şekilde çalışabilmesi sağlanmıştır. Tasarlanan sistem mikrokontrolcü tabanlı, portatif ve küçük boyutlu bir sistem olduğu için büyük bir kullanım kolaylığına sahiptir. Donanımına ilaveten sistemin çalışması için gerekli olan gömülü sistem yazılımı da ayrıca geliştirilmiştir. Tasarlanan bu sistem ile hareket kabiliyeti sınırlı olan kişiler gündelik yaşamlarında bir gözlük yardımıyla kolay bir şekilde bilgisayar kullanabileceklerdir.

Anahtar Kelimeler: ALS, EOG, İnsan-bilgisayar arayüzü, Mikrokontrolcü, Sayısal filtreleme.

* Corresponding Author: ckeskinoglu@cu.edu.tr 


\section{Introduction}

The eye is the organ that performs the visual function in humans. The eye movements are examined by using smallamplitude biological signals that occur during the movement of the eyes. The signals mentioned are called electrooculogram (EOG) signals, and this method is called electrooculography. The source of the EOG is the corneal-retinal potential due to hyperpolarization and depolarization between the cornea and retina (Barea Navarro, Boquete Vázquez, \& López Guillén, 2018).

EOG signals have a frequency range of $0.1-20 \mathrm{~Hz}$ and low amplitude values such as 100 - 3500 microvolts in amplitude (Choudhury, Venkataramanan, Nemade, \& Sahambi, 2005). Therefore, the EOG signals obtained must be amplified appropriately.

In the literature, there are many studies using EOG signals. For example, there are studies about the processing of signals received with electrodes placed around the eye, understanding the state of the eye, and studies in different areas such as sleep examination with the help of EOG signals (Kuo \& Chen, 2020; Rahman, Bhuiyan, \& Hassan, 2018). Recently, studies aiming to help people with diseases that negatively affect mobility (such as paralysis and ALS) perform their daily tasks by using EOG signals and thus can improve their quality of life are pretty popular (Jialu et al., 2018; Ramakrishnan et al., 2021). Reintegration of these people into society is very important both individually and socially.

There are studies in the literature in which EOG signals are used to control devices, especially wheelchairs. Huang et al. used EOG signals in wheelchair control. They stated that their proposed human-computer interface design could perform more commands with higher accuracy with fewer electrodes than other systems in the literature (Huang et al., 2017). In another study, Huang et al. controlled a wheelchair and a robotic arm attached to it with a hybrid method that used electroencephalography (EEG) and EOG. In this study, they held the movements of the chair to the right and left direction by using EEG signals obtained by the imagination of these movements, and used EOG in the forward, backward, and stopping movements of the chair, and in the control of the robotic arm (Huang, Zhang, Yu, He, \& Li, 2019). In addition to these studies, there are also different studies in which EOG signals are used in device control (Bhuyain et al., 2019; Huang, Chen, et al., 2019; T. Li, Yang, Bai, \& Wang, 2018; Y. Li, He, Huang, Gu, \& Yu, 2018).

Another field of study where EOG signals are frequently used is human-computer interface studies. In these studies, people with limited mobility can easily achieve tasks such as controlling computers, surfing on the internet, etc., with eye movements. He et al. proposed a hybrid method based on EEG and EOG for computer mouse control in their study. In this way, people can perform operations such as writing and accessing the internet without any serious movement. In this study, while they used EEG signals for horizontal movement of the mouse, EOG signals were used for vertical movement, click and select (He et al., 2020). In another study, He et al. showed that writing could be performed with a keyboard in the interface using only EOG signals (He \& Li, 2017). Heo et al. developed a wearable EOG measurement system worn on the head by proposing a different electrode array for the human-computer interface (Heo, Yoon, \&
Park, 2017). Yang et al. developed an EOG-based braincomputer interface and used piecewise linear estimation (PLA) and support vector regression (SVR) methods in their studies. Unlike the other studies, they also measured the electromyography(EMG) signals in the temporal region (Yang, Gang, \& Kim, 2018). Different studies based on EOG for human-computer interface applications are also available in the literature (Hosni, Shedeed, Mabrouk, \& Tolba, 2019; Kaur, Singh, \& Singh, 2017; Lin et al., 2019; Teng et al., 2020).

In this study, EOG and microcontroller-based low-cost, small, and portable computer control systems were designed and implemented for brain-computer interface applications. With this system, it is aimed that people whose mobility is partially or completely limited can use the computer by controlling the cursor on the computer with only eye movements. The EOG signals were acquired in real-time via special glasses with integrated $\mathrm{Ag} / \mathrm{AgCl}$ electrodes in the study. These received signals were amplified with the instrumentation amplifier and filtered digitally. In this way, the mouse cursor could be controlled. Unlike the other studies in the literature, the number of electronic components was considerably reduced in the design, so more stable, lower cost, and the smaller device could be designed. In addition to this, a more effective device has been introduced since a digital filter is used in the study. In the study, thanks to the glasses with integrated electrodes used to collect EOG signals, the system has great ease of use and can be controlled without connecting any external electrode to the person. In the second part of the study, the system's design, acquiring and processing EOG signals, and the developed software was explained. In the last part of the study, the study's results and the study's comparison with other studies were mentioned.

\section{Material and Method}

\subsection{Circuit Designing and Hardware}

In this study, a system that can control the mouse cursor on a computer using EOG signals has been developed for people with limited mobility. The EOG signals were acquired with glasses with integrated electrodes from the user's eye movements in both vertical and horizontal axes in the design. The glasses used can be attached to the head with an adjustable band, and they can be narrowed and expanded according to the person's head size. In this way, it does not cause any discomfort in the head of the user. There are the electrodes on the side, bottom, and upper parts of the glasses that will collect the signal from the user. The glasses used in the study are shown in Figure 1.

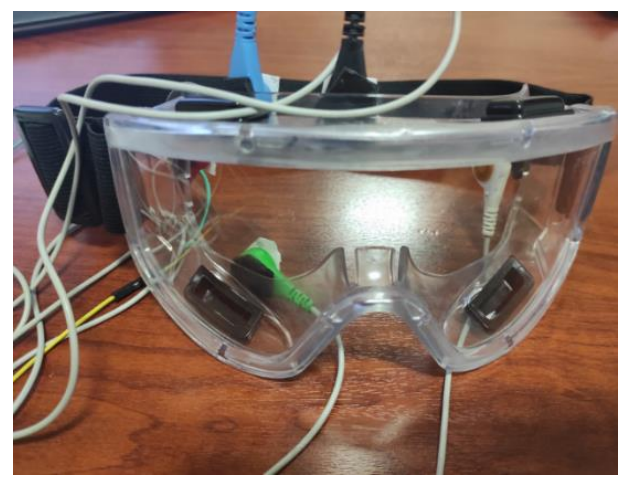

Figure 1: The glasses used for collecting EOG signals. 
In the study, the EOG signals in both axes were taken in real-time with glasses, and the channel was selected with the multiplexer. Then, these signals were amplified with an instrumentation amplifier. The amplified signals were read with the microcontroller, and then the system was calibrated with the first of these signals. The signals were filtered digitally, as there may be noise affecting the system negatively in these signals due to facial movements. The mouse is adequately controlled by using the filtered signals. The block diagram of the study is shown in Figure 2.

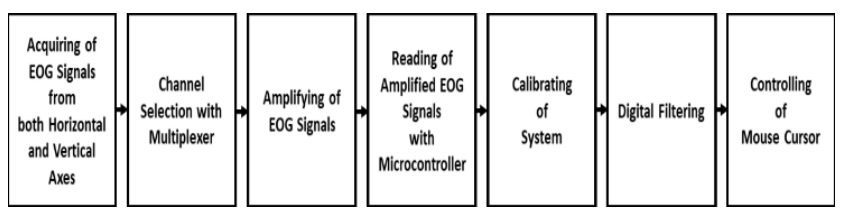

Figure 2: The block diagram of the study.

Since biopotential signals have low amplitude, they must be amplified with proper components and circuits. Therefore, the INA125 instrumentation amplifier was used in the design due to its features, such as simple gain adjustment with a single resistor, low offset voltage, and high common-mode rejection ratio. The internal structure and pin configuration of INA125 are shown in Figure 3 ("INA125 Datasheet," 1998).

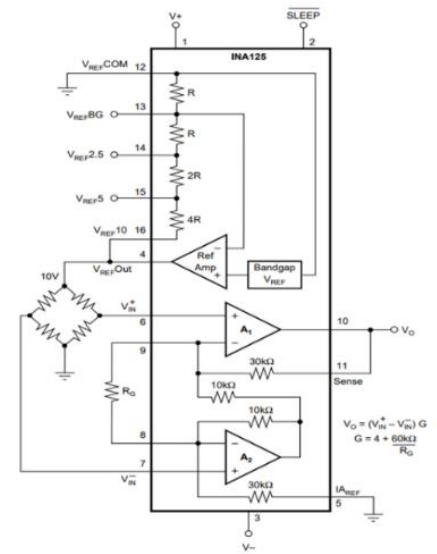

(a)

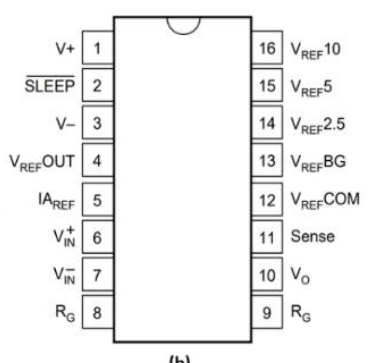

Figure 3: (a) The internal structure and (b) pin configuration of INA125 ("INA125 Datasheet," 1998).

In order to control the mouse cursor, the movements of the eye in both horizontal and vertical axes must be detected. Since a single instrumentation amplifier is used in the study to reduce the cost and device size and create a more stable device, the signals from both axes must be given sequentially to the amplifier input. For this reason, before the signal is amplified, channel selection is made quickly with a multiplexer, and the signal at the output of the multiplexer is given as input to the amplifier. In the system, CD4052BE multiplexer is used for selecting the channel. In this way, the signals acquired from both axes could be transmitted to the instrumentation amplifier quickly without interference. This multiplexer's pinout diagram is shown in Figure 4("CD4052BE Datasheet," 2017).

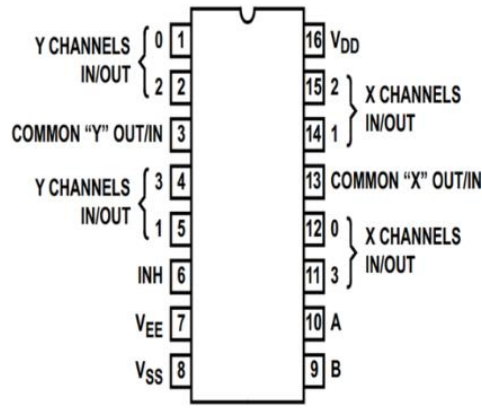

\section{Figure 4: CD4052BE multiplexer pin configuration ("CD4052BE Datasheet," 2017).}

While the multiplexer's pins of 14 and 15 were used for the positive terminals of both axes, pins of 2 and 5 were used for the negative terminals of these axes. The pins of 3 and 5 were used as output. Then this output signal was transmitted to the amplifier's input. The critical point is that the EOG signal has a very small amplitude in raw form. Therefore, the circuit will not work as expected when it is given directly to the multiplexer's input. This problem is solved by adding a DC offset to the multiplexer's inputs. The circuit diagram of the system is shown in Figure 5.

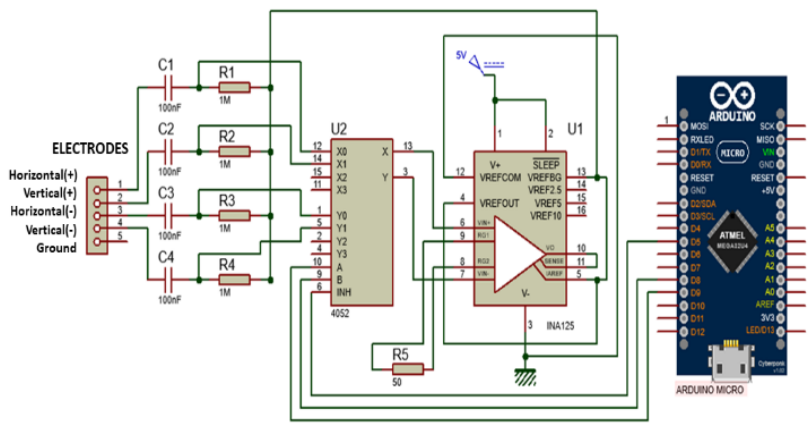

Figure 5: The circuit diagram of the system.

The power supply connections required for the circuit were provided from the power pins on the microcontroller Arduino micro. First, the raw EOG signal is passed through the $100 \mathrm{nF}$ capacitor, and so the DC components on it are filtered. Then, DC offset is added to this sign through a $1 \mathrm{M} \Omega$ resistor, and the level of signal is shifted. This shifted signal is used in the multiplexer. Otherwise, the multiplexer will not work stably at raw EOG signals with small amplitude values. In addition, the negative part of the signal can be obtained without loss by adding a DC offset. Then, the signals for both axes were transferred to the instrumentation amplifier sequentially. These signals were amplified 1204 times by using a $50 \Omega$ gain resistor. The gain formula of INA125 is given in Equation 1.

$$
G=4+\frac{60 k}{R_{G}}
$$

where $\mathrm{G}$ and $R_{G}$ represent gain and gain resistor, respectively.

The system is designed in a small size so that it can be easily used portable. The developed system is shown in Figure 6. 




Figure 6: The designed system's (a) internal view and (b) external view.

Firstly, the system is calibrated. For this, when the person looks at the computer screen's middle point, the EOG signals' amplitude values are recorded with the microcontroller. Then, these values are extracted from the acquired EOG signals each time. After this, digital filtering was performed, and the mouse cursor was controlled with this filtered signal on the computer.

In the designed system, Arduino micro is used as a microcontroller. There are several reasons for using Arduino micro. The most important reason is that it has a special library for mouse control effectively. Other reasons are its advantages such as being low cost, small size, etc.

\subsection{Electrodes Connections}

This study is necessary to detect eye movements in horizontal and vertical axes to control the mouse cursor. For this, special glasses with five $\mathrm{Ag} / \mathrm{AgCl}$ electrodes, two for horizontal movement, the other two for vertical movement, and one for ground connection, were used. The measurements were performed as bipolar measurements. The electrodes' contact points to the skin are shown in Figure 7.

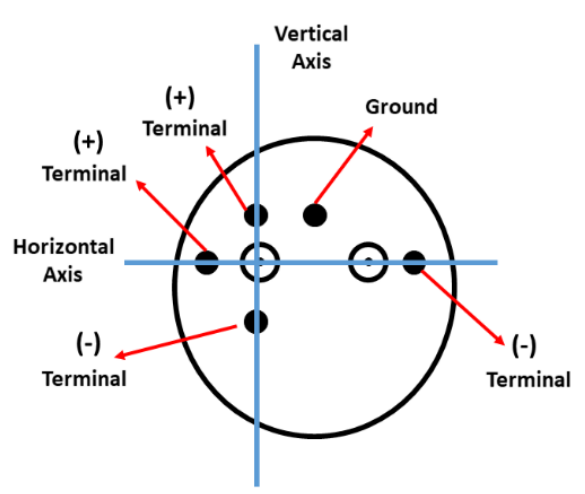

Figure 7: The electrodes' contact points to the skin.

The presence of the electrodes on the glasses without attaching directly to the face provides great ease of use, and so it prevents any discomfort to the person.

\subsection{Digital Filtering}

The EOG signal is a signal with low amplitude and frequency values. Since the eye is a moving organ, fluctuations are usually seen in the EOG signal due to the vibration movement of the eye, and these fluctuations cause problems in the evaluation of the signal with low amplitude values. Therefore, it is very important to prevent these small amplitude vibration waves in systems using the EOG signal. These fluctuations were prevented with digital filtering, and the cursor on the computer screen could be adequately controlled.

The biggest problem in digital filtering is the filter's processing load on the system. Therefore, the "leaky-integrator" filter, which does not overload the system and is a very successful method in noise prevention, was preferred in the study. When the filter's structure is examined, this filter is a kind of first-order low-pas filter that integrates the input signal and transfers it to the output according to a certain coefficient. The filter's equation is given in Equation 2.

$$
y[n]=(1-\alpha) \cdot y[n-1]+\alpha \cdot x[n]
$$

where $\mathrm{x}, \mathrm{y}$, and $\alpha$ represent input signal, output signal, and coefficient, respectively.

The $\alpha$ is less than one, and it can be adjusted according to noise in the signal. According to this coefficient, the input signal is transferred to the output at certain rates, and the noise is prevented in this way. When $\alpha$ is increased, the effect of the input signal increases on the output. In other words, the output signal is more similar to the input signal. In this situation, if the input signal is very noisy, the output signal will become noisy. Therefore, it is important to choose the $\alpha$ value appropriately. In this study, $\alpha$ is 0.85 . In this way, both the noises could be prevented and the output signal remained similar to the input signal as the waveform. The raw and filtered EOG signal obtained eye movements on the horizontal axis are shown in Figure 8.

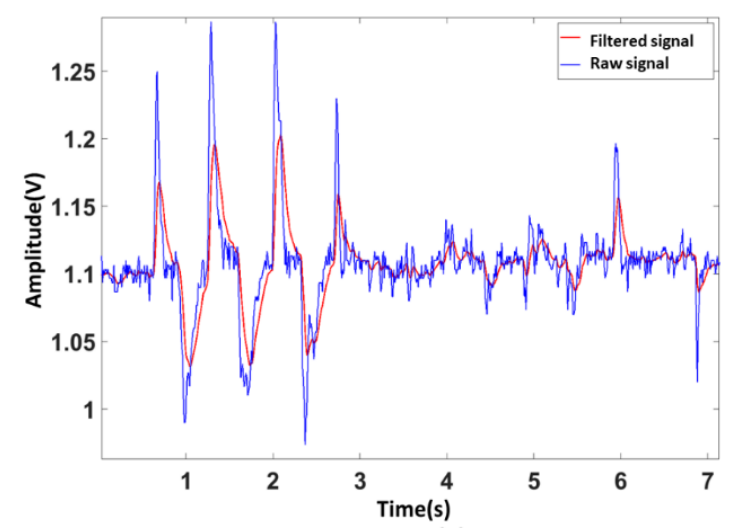

Figure 8: The raw and filtered EOG signal.

When the signals are examined, it is seen that the filter can quite prevent the noise on the input signal without distorting the waveform of the signal. The mouse cursor is controlled with this filtered signal. In addition to this, a threshold level was determined, and the cursor was optimally controlled by evaluating this threshold level. In the study, if the EOG signal has an amplitude value above the upper threshold, the cursor is moved to the right/up, and if it has an amplitude value below the lower threshold value, the cursor is moved to the left/down. In this way, the cursor is easily controlled continuously.

\subsection{Software}

In this study, embedded software has been developed using $\mathrm{C}++$ for the designed system. Operations such as acquiring the EOG signal, digital filtering, and cursor controlling have been provided with this software. The block diagram of the software is shown in Figure 9. 


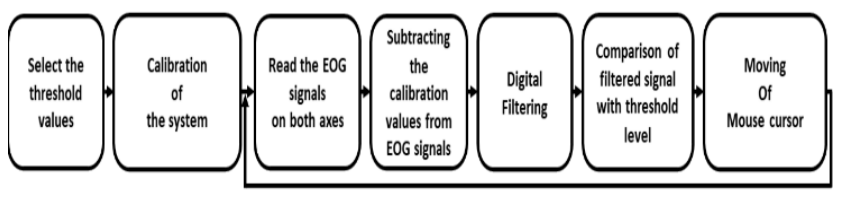

Figure 9: The block diagram of the embedded software.

In the software, firstly, the amplitude threshold levels are determined by considering the EOG signal's amplitude levels for movements in the horizontal and vertical axis. Then, the system is calibrated. After the calibration, the EOG signal is filtered, and it was controlled with threshold values, and the cursor was controlled on a computer. The designed system can operate in a repeatable and stable manner, without any different software, with just glasses. The software's pseudocode is shown in Figure 10 .

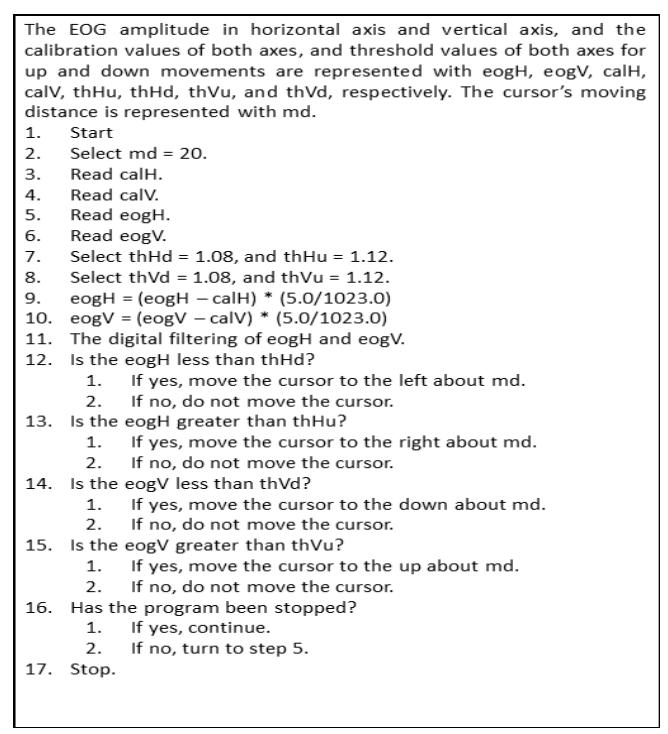

Figure 10: The software's pseudocode.

\section{Results and Discussion}

In this study, a device that provides computer control with EOG and the software required for the operation of this device have been realized. The EOG signals were acquired with the glasses, and then these signals were amplified with the designed circuit. Since there is noise on the EOG signal, digital filtering is used. In this way, the computer was controlled with EOG signals.

When this study compared previous studies in the literature, it has advantages such as low cost, more stable control, and ease to use. Similar studies in the literature have been performed by supporting different signals, such as the EEG signal. However, the cost and complexity of the system increase in these studies. Since the signals used may create and interferences, the software should be more complex for controlling the computer or other systems. In this situation, this software will tire the system as a processing load. As the cursor is controlled with just EOG in this study, an advantage is obtained about processing load compared to other studies using supporting signals.

Unlike other studies, the multiplexer was used in the device's circuit design, so the signals, both horizontal and vertical axes, could be amplified with a single instrumentation amplifier (Triadi, Wijayanto, \& Hadiyoso, 2021). Otherwise, at least two amplifiers are required to do this in both axes. In such design, since additional circuit components such as a resistor, capacitance, etc. having tolerance value use in the circuit, both the cost increases and the negative effect can occur about stability. However, as the performed study is designed with a single instrumentation amplifier, all these problems are eliminated, and a low-cost and more stable device is developed.

Another difference in this study is that digital filtering is used instead of analog filtering. In this way, the advantage is obtained about both cost and stability. If the raw and filtered EOG signal is examined, it is seen that the digital filter prevented noise effect, and the cursor is controlled successfully. The other advantage of the filter used is that its processing load is low. Thus, it has been ensured that the system can control in real-time quickly.

\section{Conclusions and Recommendations}

In this study, a low-cost, portable, and user-friendly microcontroller-based system using EOG has been developed that enables people with ALS, stroke, etc. Thus, these people can easily use a computer in their daily lives. With this device, these people can easily control the computer by moving their eyes. In this way, they will not have difficulty adapting to daily life and will easily use a computer almost used in everything in everyday life.

\section{References}

Barea Navarro, R., Boquete Vázquez, L., \& López Guillén, E. (2018). Chapter 16 - EOG-based wheelchair control. In P. Diez (Ed.), Smart Wheelchairs and Brain-Computer Interfaces (pp. 381-403): Academic Press.

Bhuyain, M. F., Shawon, M. A. K., Sakib, N., Faruk, T., Islam, M. K., \& Salim, K. M. (2019). Design and Development of an EOG-based System to Control Electric Wheelchair for People Suffering from Quadriplegia or Quadriparesis. Paper presented at the 2019 International Conference on Robotics, Electrical and Signal Processing Techniques (ICREST).

CD4052BE Datasheet. (2017). Retrieved from https://www.ti.com/lit/ds/symlink/cd4052b.pdf?ts=16211817 $\underline{65673}$

Choudhury, S. R., Venkataramanan, S., Nemade, H. B., \& Sahambi, J. (2005). Design and development of a novel EOG biopotential amplifier. IJBEM, 7(1), 271-274.

He, S., \& Li, Y. (2017). A Single-Channel EOG-Based Speller. IEEE Transactions on Neural Systems and Rehabilitation Engineering, 25(11), doi:10.1109/TNSRE.2017.2716109

He, S., Zhou, Y., Yu, T., Zhang, R., Huang, Q., Chuai, L., . . Li, Y. (2020). EEG- and EOG-Based Asynchronous Hybrid BCI: A System Integrating a Speller, a Web Browser, an EMail Client, and a File Explorer. IEEE Transactions on Neural Systems and Rehabilitation Engineering, 28(2), 519530. doi:10.1109/TNSRE.2019.2961309

Heo, J., Yoon, H., \& Park, K. S. (2017). A novel wearable forehead EOG measurement system for human computer interfaces. Sensors (Switzerland), 17(7), 1485.

Hosni, S. M., Shedeed, H. A., Mabrouk, M. S., \& Tolba, M. F. (2019). EEG-EOG based virtual keyboard: Toward hybrid brain computer interface. Neuroinformatics, 17(3), 323-341.

Huang, Q., Chen, Y., Zhang, Z., He, S., Zhang, R., Liu, J., . . . Li, Y. (2019). An EOG-based wheelchair robotic arm system 
for assisting patients with severe spinal cord injuries. Journal of neural engineering, 16(2), 026021.

Huang, Q., He, S., Wang, Q., Gu, Z., Peng, N., Li, K., . . Li, Y. (2017). An EOG-based human-machine interface for wheelchair control. IEEE Transactions on Biomedical Engineering, 65(9), 2023-2032.

Huang, Q., Zhang, Z., Yu, T., He, S., \& Li, Y. (2019). An EEG/EOG-based hybrid brain-computer interface: application on controlling an integrated wheelchair robotic arm system. Frontiers in neuroscience, 13, 1243.

INA125 Datasheet. (1998). Retrieved from https://www.ti.com/lit/ds/symlink/ina125.pdf

Jialu, G., Ramkumar, S., Emayavaramban, G., Thilagaraj, M., Muneeswaran, V., Rajasekaran, M. P., \& Hussein, A. F. (2018). Offline Analysis for Designing Electrooculogram Based Human Computer Interface Control for Paralyzed Patients. IEEE Access, 6, 79151-79161. doi:10.1109/ACCESS.2018.2884411

Kaur, N., Singh, B., \& Singh, J. (2017). MOUSE CURSOR CONTROL SYTEM BASED ON SSVEP. International Journal of Advanced Research in Computer Science, 8(7).

Kuo, C.-E., \& Chen, G.-T. (2020). A Short-Time Insomnia Detection System Based on Sleep EOG With RCMSE Analysis. IEEE Access, 8, 69763-69773.

Li, T., Yang, J., Bai, D., \& Wang, Y. (2018). A New Directional Intention Identification Approach for Intelligent Wheelchair Based on Fusion of EOG Signal and Eye Movement Signal. Paper presented at the 2018 IEEE International Conference on Intelligence and Safety for Robotics (ISR).

Li, Y., He, S., Huang, Q., Gu, Z., \& Yu, Z. L. (2018). A EOGbased switch and its application for "start/stop" control of a wheelchair. Neurocomputing, 275, 1350-1357. doi:https://doi.org/10.1016/j.neucom.2017.09.085

Lin, C., King, J., Bharadwaj, P., Chen, C., Gupta, A., Ding, W., \& Prasad, M. (2019). EOG-Based Eye Movement Classification and Application on HCI Baseball Game. IEEE Access, $\quad 7, \quad 96166-96176$. doi:10.1109/ACCESS.2019.2927755

Rahman, M. M., Bhuiyan, M. I. H., \& Hassan, A. R. (2018). Sleep stage classification using single-channel EOG. Computers in Biology and Medicine, 102, 211-220. doi:https://doi.org/10.1016/j.compbiomed.2018.08.022

Ramakrishnan, J., Sivasakthivel, R., Akila, T., Retnadhas, M., Uthup, T. T., \& Mythily, R. (2021). Electrooculogram-aided intelligent sensing and high-performance communication control system for massive ALS individuals. The Journal of Supercomputing, 1-18.

Teng, G., He, Y., Zhao, H., Liu, D., Xiao, J., \& Ramkumar, S. (2020). Design and development of human computer interface using electrooculogram with deep learninG. Artificial intelligence in medicine, 102, 101765.

Triadi, T., Wijayanto, I., \& Hadiyoso, S. (2021). Electrooculogram (EOG) based Mouse Cursor Controller Using the Continuous Wavelet Transform and Statistic Features. Lontar Komputer: Jurnal Ilmiah Teknologi Informasi, 12(1), 53-61.

Yang, J.-J., Gang, G. W., \& Kim, T. S. (2018). Development of EOG-based human computer interface (HCI) system using piecewise linear approximation (PLA) and support vector regression (SVR). Electronics, 7(3), 38. 